\title{
Urinary Exosomes for Protein Biomarker Research
}

\author{
Delfin Albert Amal Raj ${ }^{1,2}$, Immacolata Fiume1, \\ Giovambattista Capasso ${ }^{2}$ and Gabriella Pocsfalvi ${ }^{1}$ \\ ${ }^{1}$ Mass Spectrometry and Proteomics, \\ Institute of Protein Biochemistry - CNR, Naples \\ ${ }^{2}$ Department of Internal Medicine, Chair of Nephrology, \\ Faculty of Medicine, Second University of Naples, Naples \\ Italy
}

\section{Introduction}

Exosomes represent a distinct class of membrane nanovesicles of endocytic origin that are released to the extracellular microenvironment from diverse cell types under both physiological and pathological conditions. Remarkable roles of exosomes have been revealed in intercellular communication, immune regulation, infection, aging and cancer. Exosomes carry and transfer proteins, nucleic acids and lipids, and are ubiquitous in most biofluids, such as urine, plasma, cerebrospinal fluid, etc. Membrane vesicles secreted by the epithelial cells of the urinary tract hold the promise to be an excellent source of disease relevant cargo proteins. In clinical proteomics urine is one of the most attractive biofluids as it can be obtained non-invasively, in large quantities and is relatively stable. Current isolation methods however are not sufficiently proficient to produce urinary exosomes (UEs) at a purity grade and with reproducibility suitable for downstream LC-MS based quantitative proteomics applications. Consequently urinary exosome based protein biomarker research today exclusively relies on targeted protein studies (Table 1).

This chapter describes the current state-of-the-art in exosome research in general and urinary exosomes in particular with a special focus on the potential of UEs in protein biomarker discovery. Recently we have developed an improved isolation/purification method based on double-cushion sucrose $/ \mathrm{D}_{2} \mathrm{O}$ ultracentrifugation (Raj et al., 2011b). The method relies on the solubilization of the major impurities associated with UEs in a carefully selected buffer solution. The new method separates exosomes from the heavier membrane fragments and/or vesicles more efficiently than current protocols and is compatible with LC-MS-based quantitative proteomics workflow.

\section{Cell-derived exosomes: Biogenesis, composition and biological role}

Cells rely on two basic mechanisms for active, vesicle-mediated macromolecular transport through the cellular plasma membrane: exocytosis and endocytosis (Figure 1). Both make use of membrane vesicles for the packaging and trafficking of molecules. While endocytosis is the process in which the extracellular substances enter into a cell without directly passing 
through the cell membrane, exocytosis is the primary means of cellular secretion. During both constitutive and regulated exocytosis the secretory-vesicles dock and/or fuse with the plasma membrane. Endocytic pathway (EP), which is primarily responsible for the uptake, trafficking and sorting of internalized proteins has a role in vesicle secretion too (Thery et al., 2002). In the EP, transmembrane proteins are sorted into lumenal vesicles of multivesicular bodies (MVBs). MVBs can have different destinies: they can fuse or mature with lysosomes where the degradation of their protein cargo takes place, or can fuse with the cell membrane to secrete the intraluminal vesicles (ILVs) into the extracellular space. These extracellularly released ILVs are called exosomes (Gruenberg et al., 2004, Keller et al., 2006). During this process, the second inward budding of the endosome membrane results in a positive orientation of the ILVs lipid membrane. Thus when the ILVs are released to the extracellular environment, they have the same orientation as the cell membrane and have been shown to display many of the surface markers from their cell of origin (Thery et al., 2002). The sorting process of membrane proteins during ILV formation is considered to be an active process and thus, exosomal surface proteins seem not to be a plain one-to-one representation of the surface markers for the cell of origin.

While the regulation of endocytic cargo sorting and its delivery to lysosomes have been extensively studied (Williams et al., 2007) relatively less is known about the factors which regulate the formation, the release and the cargo sorting into vesicles destined to be exosomes. The involvement of ubiquitinization and ESCRT (endosomal sorting complex required for transport) protein complexes have been shown by different groups (Gan et al., 2011, Shen et al., 2011). Though, ESCRT-independent mechanisms by means of ceramidemediated budding of exosomes into ILVs within the MVBs have also been identified (Marsh et al., 2008, Trajkovic et al., 2008). Further evidence of ESCRT-independent pathway of ILV formation has come from studying the protein Pmel17, a main component of the c fibrils of pre-melanosomes, which is targeted to intraluminal vesicles of MVBs independently of ubiquitination, ESCRT0 and ESCRTI (Raposo et al., 2001). The most recent model on the formation of ILVs combines the lipid-driven membrane deformation theory with the ESCRT-regulated sorting mechanism (Babst, 2011).

Microvesicles (MVs) are generated by the outward budding and fission of membrane vesicles from the cell surface (Fig. 1) (Lee et al., 2011). MVs (100-1000 nm) are generally bigger in size than exosomes $(30-100 \mathrm{~nm})$. Yet due to the analytical difficulties in distinguishing between exosomes and $\mathrm{MVs}$, which are also shed by normal and diseased cells, they are often grouped together.

Many mammalian cells like dendritic, mast, epithelial, neural, stem and hematopoietic cells, reticulocytes, astrocytes, adipocytes, and tumor cells have been reported to release exosomes (Denzer et al., 2000, van Niel et al., 2006). Exosomes purified from the cell culture supernatants are usually heterogeneous in size and contain functional mRNA translatable to proteins, mature microRNAs, lipids and proteins. Proteins of exosomes have been analyzed both by proteomics and targeted immunochemical methods, like Western-blot, FACS with immunolabeling, and immunoelectron microscopy. Protein composition analysis of exosomes shows a rather limited sub-cellular localization for the exosomal proteins. In fact, usually the preparations of exosomes are mostly enriched in cytosolic and membrane proteins and contain less proteins of nuclear, mitochondrial, endoplasmic-reticulum or Golgi-apparatus origin. Secondly, exosomes express a common set of proteins. These are structural components and proteins with a role in exosome biogenesis and trafficking. Cell type specific components which presumably reflect the biological function of the parent cell on 


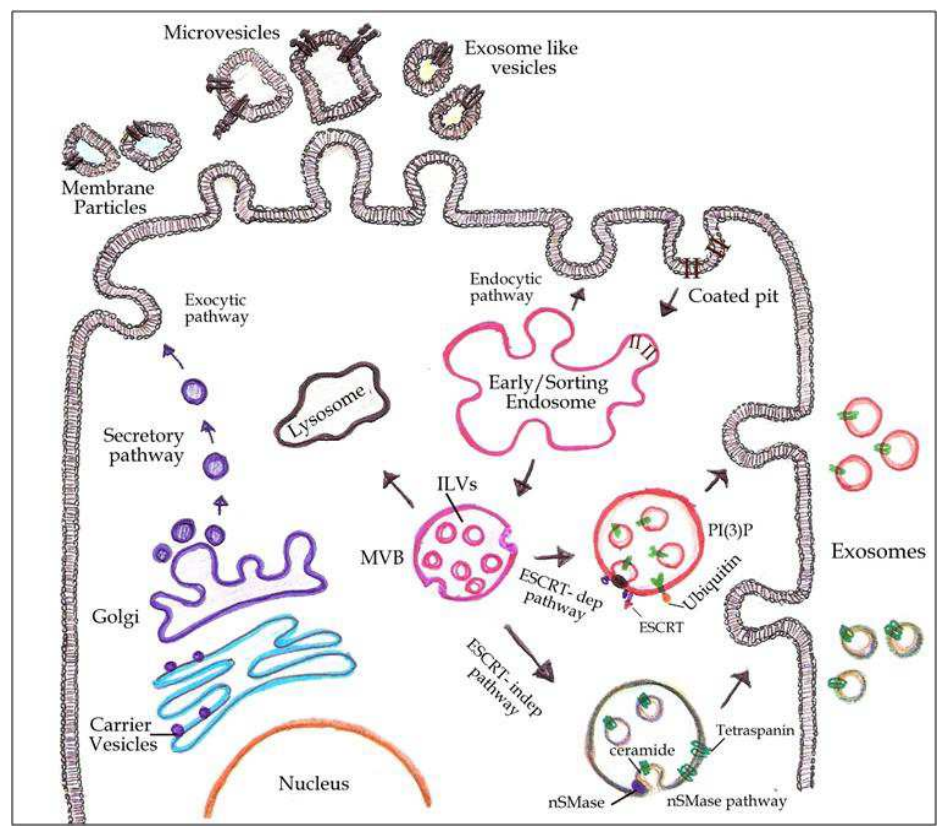

Fig. 1. Schematic representation of extracellular vesicles biogenesis. The formation, release and cargo sorting into vesicles destined to be exosomes may involve: i) ESCRT dependent pathway - involving the ubiquitination and ESCRT protein complexes and ii) ESCRT independent pathway - like ceramide mediated budding. Microvesicles, membrane particles and exosome like vesicles are secreted by outward budding or fission from the cell surface.

the other hand could also be identified in exosome preparations (van Niel et al., 2006). Protein contents of exosomes from different cells have been mapped by proteomics and the most of the data obtained has been catalogued in Exocarta database (Mathivanan et al., 2009).

Despite their role in immune system modulation ( $\mathrm{Li}$ et al., 2006), the biological role of exosome secretion remained largely elusive until recent years when Lötvall's group demonstrated that exosomes can transfer genetic information from one cell to another (Valadi et al., 2007, Taylor, 2010). Since then several mechanisms have been proposed to describe exosome-cell interactions: (i) cellular binding via conventional receptor-ligand interactions, similar to cell-cell communication. (ii) attaching/fusing with target cell membrane and (iii) internalization by recipient cells by endocytosis in a transcytotic manner. Besides the physiological roles of exosomes to remove the unwanted cellular debris, recent findings uncover an entirely new and exciting modes of cell-cell communication and paracrine signalling mediated by exosomes (Thery et al., 2002, Camussi et al., 2011). Emerging data shows their involvement in different diseases including inflammation, renal diseases, Alzheimer diseases, aging, bacterial and viral infections, allergies and cancer. Using different sources of tumor-derived exosomes, several groups claim that exosomes can prevent tumor development, induce tumor specific immunity, and provide a possible strategy for therapeutic tumor vaccination reviewed by van Niel et al. (van Niel et al., 2006). 


\section{Urinary exosomes}

\section{1 mRNA, miRNA and protein biomarkers in urinary exosomes}

Urinary exosomes originate from those ILVs that are shed into the urinary space by the fusion of the outer membrane of MVBs with the apical plasma membrane of cells lining the urinary tract, including glomerular podocytes, renal tubule cells, and bladder. The number, and the physical, chemical and biological properties of UEs may change over time in association with disorders that affect the urinary system. Respect to the total urine sample, UEs result in a remarkable enrichment of low-abundance biomolecules with potentially high diagnostic value regarding the physiological and pathological state of the renal system. Therefore, it is not surprising that there is a great interest in the use of UEs as a novel biomarker source for early disease detection, classification, prediction severity, outcome and response to treatment. Since the first publication on proteomic profiling of UEs by the group of Knepper (Pisitkun et al., 2004), an increasing number of articles with keywords "exosome and urine" are to be found in the PubMed database. The principal aim of urinary exosome research today is to discover mRNA, microRNA and protein biomarkers.

\begin{tabular}{|c|c|c|c|c|c|c|c|}
\hline Disease & Isolation method & $\begin{array}{c}\text { Protein } \\
\text { separation }\end{array}$ & $\begin{array}{c}\text { Protein } \\
\text { identification }\end{array}$ & Quantitation & $\begin{array}{c}\text { Protein Biomarker } \\
\text { candidate }\end{array}$ & Taxonomy & Ref \\
\hline AKI & $\begin{array}{l}\text { differential } \\
\text { ultracentrifugation }\end{array}$ & 2D-PAGE & $\begin{array}{l}\text { MS } \\
\text { Western blot }\end{array}$ & 2D-PAGE & Fetuin-A & $\begin{array}{l}\text { Rat } \\
\text { Human }\end{array}$ & $\begin{array}{l}\text { Zhou et al., } \\
2006 \mathrm{a}\end{array}$ \\
\hline AKI & $\begin{array}{l}\text { differential } \\
\text { ultracentrifugation }\end{array}$ & SDS-PAGE & Western blot & Western blot & $\begin{array}{l}\text { ATF3 } \\
\text { WT-1 }\end{array}$ & \begin{tabular}{|l} 
Rat \\
Human
\end{tabular} & Zhou et al., 2008 \\
\hline FSGS & $\begin{array}{l}\text { nanomembrane } \\
\text { concentration }\end{array}$ & SDS-PAGE & $\begin{array}{l}\text { MS } \\
\text { Western blot }\end{array}$ & Western blot & Podocalyxin & Human & $\begin{array}{l}\text { Cheruvanky et } \\
\text { al., } 2007\end{array}$ \\
\hline$B C$ & $\begin{array}{l}\text { differential } \\
\text { ultracentrifugation }\end{array}$ & SDS-PAGE & MS & $\begin{array}{l}\text { Spectral } \\
\text { count }\end{array}$ & \begin{tabular}{|l} 
Resistin \\
GTPase NRas \\
EPS8L2 \\
Mucin-4 \\
EPS8L1 \\
RAI3 \\
GSA \\
EHDP4 \\
Galectin-3 \\
\end{tabular} & Human & $\begin{array}{l}\text { Smalley et al., } \\
2008\end{array}$ \\
\hline PC & \begin{tabular}{|l} 
sucrose cushion \\
ultracentrifugation
\end{tabular} & SDS-PAGE & Western blot & Western blot & \begin{tabular}{|l} 
PSA \\
PSMA \\
\end{tabular} & Human & \begin{tabular}{|l} 
Mitchell et al., \\
2009
\end{tabular} \\
\hline $\mathrm{I} / \mathrm{R}$ & \begin{tabular}{|l} 
differential \\
ultracentrifugation
\end{tabular} & SDS-PAGE & Western blot & Western blot & AQP1 & \begin{tabular}{|l|} 
Rat \\
Human
\end{tabular} & \begin{tabular}{|l} 
Sonoda et al., \\
2009
\end{tabular} \\
\hline GKD & $\begin{array}{l}\text { sucrose gradient } \\
\text { ultracentrifugation }\end{array}$ & SDS-PAGE & Western blot & Western blot & ADAM10 & Human & $\begin{array}{l}\text { Gutwein et al., } \\
2010\end{array}$ \\
\hline NSCL & $\begin{array}{l}\text { differential } \\
\text { ultracentrifugation }\end{array}$ & SDS-PAGE & $\begin{array}{l}\text { MS } \\
\text { Western blot }\end{array}$ & Western blot & LRG1 & Human & Li et al., 2011 \\
\hline
\end{tabular}

AKI - acute kidney injury

FSGS - focal segmental glomerulosclerosis

BC - bladder cancer

PC - prostate cancer

$\mathrm{I} / \mathrm{R}$ - renal ischemia/reperfusion

GKD - glomural kidney disease

NSCL - non-small cell lung cancer

Table 1. Different isolation/purification, protein separation, identification and quantitation methods used in urinary exosome related targeted protein biomarker studies. 
mRNA transcripts encoding specific genes from various regions of the nephron, the collecting duct, the prostate and the bladder have been isolated from urinary exosome preparations (Miranda et al., 2010, Keller et al., 2011). Interestingly, RNA of UEs was found to be protected from RNase degradation which may suggest a functional role for the nucleic acids present in exosome (Keller et al., 2011). In the mRNA sample isolated from the urinary exosomes of prostate cancer patients PCA-3 and TMPRSS2:ERG, two known prostate cancer related biomarkers were detected (Nilsson et al., 2009). Urinary exosomes seem to be particularly rich in miRNAs too. The use of miRNA as diagnostic biomarkers in exosome research is an emerging field due to important potential advantages over standard mRNA (Li et al., 2010).

There are over a thousand proteins identified from UE preparations published in the Exocarta (Mathivanan et al., 2009) and the Urinary Exosome Protein Database (Pisitkun et al., 2004) including the six exosome markers commonly used in exosome research (Alix, Tsg101, CD63, CD9, CD81, HSP70). Proteins of UEs show a different profile from that of total urinary proteins but with a high degree of overlap. UEs are enriched in membrane and cytosolic cargo proteins from the different epithelial cells lining the urinary tract (Pisitkun et al., 2004, Gonzales et al., 2009). For clinical biomarker discovery, LC-MS based large-scale quantitative proteomic analysis would be the method of choice. However, at the urinary exosome level it is still a daunting task (Gonzales et al., 2008, Mitchell et al., 2009, Keller et al., 2011). Therefore, protein quantitation and expression analysis has mainly been performed by targeted studies like antibody-based Western blot analysis (Table 1). For this reason only a few protein biomarker candidates have so far been identified in UEs.

\subsection{Isolation and purification}

Protocols for collection, storage and processing of human urine for exosome isolation and protein characterization have recently been published (Zhou et al., 2006b). Concerning the isolation of UEs, current methods rely on ultracentrifugation or filtration, or the combination of these two. The majority of the studies use a two-step differential centrifugation protocol developed by Pisitkun et al (Pisitkun et al., 2004). The initial step is a low velocity sequential centrifugation which serves to remove cells and cellular debris (urinary sediment) from urine, leaving the exosomes in the supernatant. The second step is the ultracentrifugation for $1 \mathrm{~h}$ to overnight of the supernatant at $100,000-200,000 \mathrm{~g}$ velocity to sediment exosomes. The major short comings of this process are the high level of contamination from uromodulin (see later) and the lack of separation of exosomes from the other MVs and membrane particles.

To obtain higher purity grade UEs, the crude preparation obtained by the two-step differential centrifugation method can be further processed using the sucrose gradient or the sucrose cushion centrifugation. Sucrose gradient centrifugation can be performed on linear or step gradients typically using sucrose concentrations between $2.0 \mathrm{M}-0.25 \mathrm{M}$ (Keller et al., 2007, Hogan et al., 2009, Simpson et al., 2009, Mathivanan et al., 2010). Instead of gradient, a small density cushion typically composed of $30 \%$ sucrose in deuterium oxide $\left(\mathrm{D}_{2} \mathrm{O}\right)$, can also be employed for the purification of UEs (Mitchell et al., 2009, Simpson et al., 2009, Welton et al., 2010). In the sucrose cushion, formation of a mini density gradient takes place in the range of $1.10-1.18 \mathrm{~g} / \mathrm{cm}^{3}$. This range was shown to be suitable to enrich and purify exosomes preventing vesicle aggregation that pelleting could cause. Sucrose gradient and cushion centrifugations thus allow a better separation of exosomes from the vesicles of different densities respect to the differential centrifugation 
method, however it does not seem to eliminate the problem of the co-purifying uromodulin (Hogan et al., 2009).

Filtration-based protocols generally use polyether sulfone nano-membranes in a spin concentrator to isolate urinary exosomes (Cheruvanky et al., 2007). The method is simple, fast and is capable to isolate UEs from small volumes of urine $(0.5-10 \mathrm{~mL})$. Therefore it is very promising, especially for mRNA and miRNA based exosome biomarker research. Drawbacks of this method for protein biomarker research are the low yield and the high level of contamination caused by urinary proteins binding to the filter. To overcome this, recently a low protein binding membrane (hydrophilized polyvinylidene difluoride) has been used to isolate urinary exosomes (Merchant et al., 2010).

\subsection{The uromodulin problem}

Current methods are characterized by a high and variable level of uromodulin contamination (Hogan et al., 2009, Fernandez-Llama et al., 2010, Rood et al., 2010). Uromodulin, also referred to as Tamm-Horsfall glycoprotein, is a major glycoprotein produced by kidney cells. Uromodulin assembles into intracellular filaments in urine (Porter et al., 1955, Schaeffer et al., 2009). The filaments have an average width and length of $100 \AA$ and $2.5 \mu \mathrm{m}$, respectively and tend to form a three-dimensional matrix with pores as shown by electron microscopy (Porter et al., 1955). This filament network traps exosomes and prevents their efficient isolation and purification by traditional methods. The uromodulin problem is one of the bottle neck of UE protein research because it considerably reduces sample yield and reproducibility (FernandezLlama et al., 2010). In order to facilitate the removal of high molecular weight aggregates recently, dithiothreitol (DTT) was applied to reduce the intermolecular disulfide bonds of uromodulin (Pisitkun et al., 2004, Fernandez-Llama et al., 2010). Treatment with DTT result in a higher yield of urinary exosomes. Notwithstanding it does not solve the problem efficiently. For this reason, urinary exosome samples prepared by the current methods are far from being ideal for quantitative proteomic analysis.

\section{Interfacing urinary exosome isolation/purification and lysis with quantitative proteomics for protein biomarker research}

Biomarkers support the diagnosis and medical management of various disorders. The remarkable progress made in proteomic technologies in the past decade have enabled researchers to consider designing studies to identify diagnostic and therapeutic biomarkers by analyzing complex proteome samples using unbiased mass spectrometry based methods. In urinary exosome research this has been hampered by the high and variable concentration of uromodulin causing low sample quantity, quality and low reproducibility. To meet the need of a global protein biomarker discovery platform we have set-up new protocols for the isolation/purification and also for the lysis and subsequent solubilization of membrane proteins. Paragraph 4.1 describes a novel urinary exosome preparation called doublecushion ultracentrifugation method and paragraph 4.2 shows its compatibility with downstream analysis.

We have employed a multiplex quantitative proteomics method, iTRAQ (isobaric Tagging for Relative and Absolute protein Quantification), in conjunction with multidimensional chromatography, followed by tandem mass spectrometry (MS/MS), to measure relative differences in the protein composition of urinary exosome samples (Figure 2). The aim of this work was to compare the protein content of UEs obtained by single- and double- 


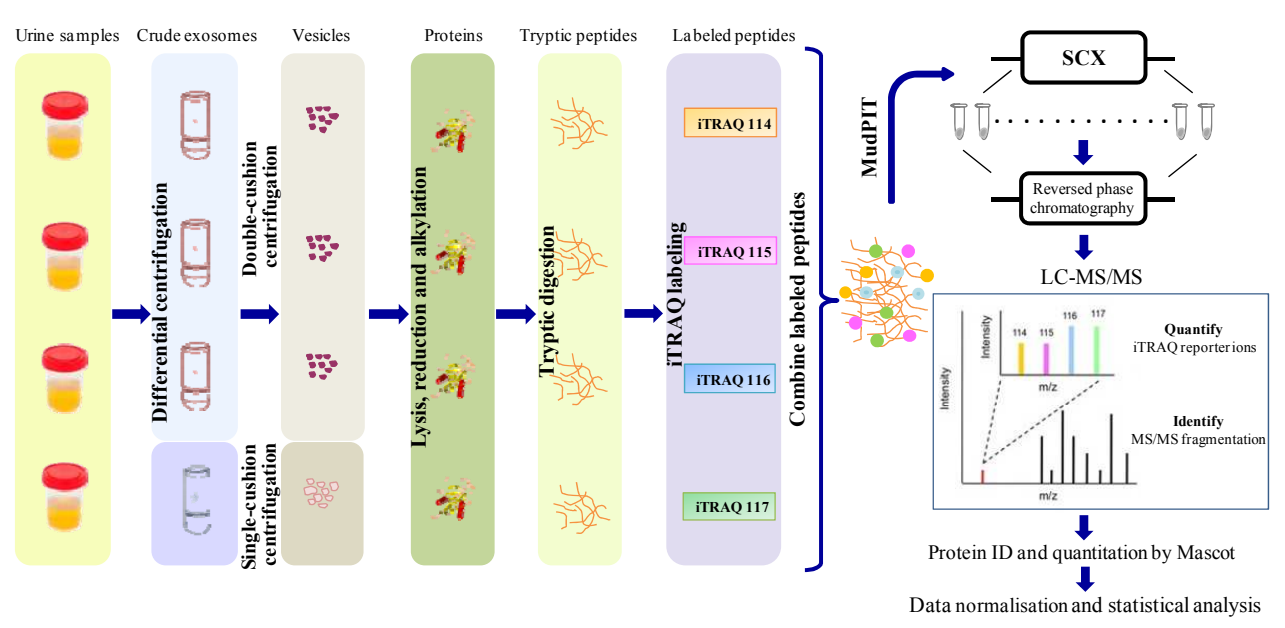

Fig. 2. Scheme of the MudPIT based 4-plex iTRAQ quantitative analysis comparing the double-cushion ultracentrifugation method with that of single-cushion.

cushion ultracentrifugation methods. Simultaneously, we compared samples obtained from a single person with a pool of healthy volunteers divided into two age groups (25-50 years and 50-70 years) in order to study feasibility of analysis of single patient versus pooled samples in the discovery phase of protein biomarker research.

\subsection{A novel isolation/purification method based on uromodulin solubilization and double-cushion ultracentrifugation}

The urinary exosome isolation/purification method which we have recently developed (Raj et al., 2011b) employs a double-cushion ultracentrifugation step performed in a carefully chosen buffer solution. Respect to other ultracentrifugation based methods which generally use a PBS buffer $(150 \mathrm{mM} \mathrm{NaCl}$ at $\mathrm{pH} 7.2)$ the novel method employs a solubilising buffer composed of $20 \mathrm{mM}$ Tris at $\mathrm{pH}$ 8.6. We have found that Tris buffer efficiently solubilizes uromodulin aggregates, keeps uromodulin in solution and does not lyses exosomes. This is in accordance with a previous in vitro study on uromodulin solubility which underlines the importance of alkaline $\mathrm{pH}$, low sodium and calcium concentrations and sample dilution to prevent the formation of uromodulin aggregates (Kobayashi et al., 2001). After solubilizing the pellet obtained in the differential ultracentrifugation step, double-cushion ultracentrifugation is performed. The double-cushion is made of sucrose $1 \mathrm{M}$ and sucrose 2 $\mathrm{M}$ prepared in $20 \mathrm{mM}$ Tris $\mathrm{pH} 8.6$ in $\mathrm{D}_{2} \mathrm{O}$ and subsequently under layered below the sample in the centrifuge tube. This step was found to considerably improve the separation of exosomes from the heavier vesicles and/or membrane fragments.

\subsection{Analysis of urinary vesicles at the various steps of isolation/purification}

Exosomes were purified from pooled urine samples of ten healthy donors and separated on $4-12 \%$ gradient polyacrylamide gel then stained with colloidal Coomassie blue. SDS-PAGE analysis at the various phases of the isolation/purification process is shown in Figure 3.

Total urinary protein profiles before (Figure 3.A, Lane 1) and after exosome depletion (Figure 3.A, Lane 2) do not markedly differ from each other and show the typical pattern of 
A

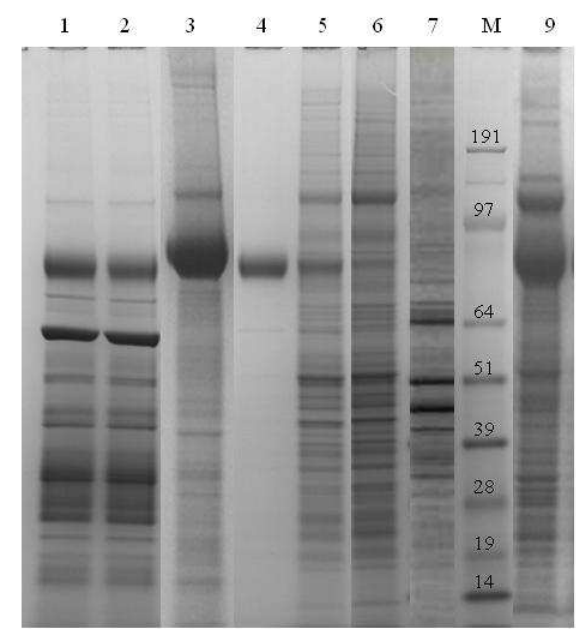

B

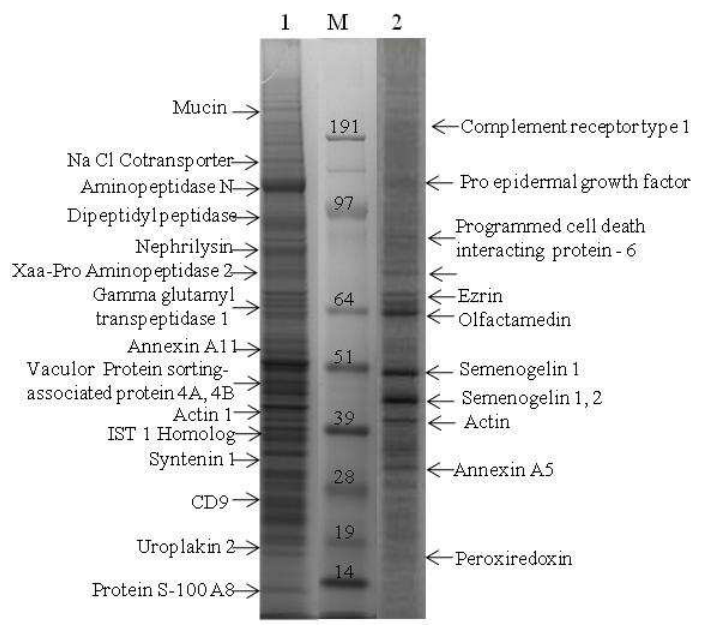

Fig. 3. SDS PAGE analyses A) at the different stages of urinary exosome

isolation/purification through the double-cushion (lanes 1-7) and the single-cushion (lane 9) methods and, B) of the $1 \mathrm{M}$ and $2 \mathrm{M}$ sucrose fractions obtained after the double-cushion ultracentrifugation method (major proteins identified by in-gel digestion proteomics are indicated next to the band). Lanes in Figure A as follow: 1- Total urine; 2- Exosome depleted urine; 3- Crude exosome fraction after differential centrifugation; 4- 15,000g pellet; 5- 15,000g supernatant; 6- Purified exosomes (1 M sucrose fraction); 7- 2 M sucrose fraction; M- Protein molecular weight markers $(\mathrm{kDa})$; 9 - Urinary exosomes prepared by the single sucrose $/ \mathrm{D}_{2} \mathrm{O}$ cushion method. Lanes in Figure B are as follow: 1- $1 \mathrm{M}$ sucrose fraction and 2- $2 \mathrm{M}$ sucrose fraction and $\mathrm{M}$ - Protein molecular weight markers (kDa).

the major urinary proteins, like albumin, various IgG chains, uromodulin etc. After the twostep differential centrifugation the crude exosome pellet (Figure 3.A, lane 3) still contains a considerable amount of contaminating urinary proteins and in particular uromodulin at 85 $\mathrm{kDa}$. These are in part removed after the solubilization step by low-speed centrifugation (Figure 3.A, lane 4-5) and, in part by the double-cushion ultracentrifugation. The later yields two fractions: the $1 \mathrm{M}$ sucrose fraction which contains the exosome vesicles (Figure 3.A, lane 6) and the $2 \mathrm{M}$ fraction which contains vesicles heavier than exosomes (Figure 3.A, lane 7). The efficiency of the uromodulin removal by the double-cushion sucrose ultracentrifugation methods can be appreciated by comparing the $1 \mathrm{M}$ fraction (Figure 3.A, lane 6) with the crude exosome fraction (Figure 3.A, lane 3) and with the exosomes purified by the singlecushion method (Figure 3.A, lane 9). In Figure 3.B SDS-PAGE image of the two vesicle containing fractions, $1 \mathrm{M}$ (lane 1) and $2 \mathrm{M}$ (lane 2) are shown together with the major proteins identified in the gel bands. It is of note that not only the protein pattern but also the proteins identified in the major SDS-PAGE bands were found to be different, indicating the presence of two different types of vesicles in the two fractions. Semenogelin 1 and semenogelin 2 and olfactomedin for example have previously been identified in prostasomes, i.e. the secretory particles in human seminal fluid (Utleg et al., 2003). Therefore it is plausible to presume that the $2 \mathrm{M}$ sucrose fraction contains heavier vesicles, like urinary secreted prostasomes. 
Western blot analysis was performed to monitor the enrichment in exosomes and the reproducibility of sample preparation by the double-cushion ultracentrifugation. Exosomal proteins were separated on 4-12\% gradient SDS-PAGE and electro blotted to PVDF membrane. Blots were probed with antibodies against two known exosome markers Alix and TSG101, together with NKCC2 a renal sodium transporter known to be present in urinary exosomes (Figure 4.). The enrichment of exosomes is excellent in the samples prepared by the doublecushion (Figure 4., lane 4-6) respect to the starting and exosome depleted urine samples (Figure 4., lane 2-3) and also to the sample prepared by the differential centrifugation method (Figure 4., lane 1). Importantly a very high degree of reproducibility was achieved in three independent urinary exosome preparations (Figure 4., lanes 4-6).

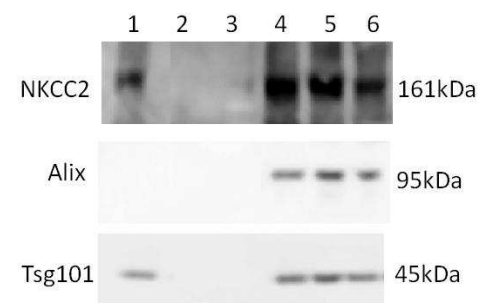

Fig. 4. Western blot analysis of urinary exosomes prepared by two different methods. Lane 1- Exosome purified by differential centrifugation; Lane 2- Total urine; Lane 3- Exosome depleted urine; Lane 4-6 - Exosomes purified in three independent experiments from pooled urine samples of ten healthy volunteers by the double-cushion method.

Exosome-like vesicles isolated from culture supernatant are limited by a lipid bilayer and in literature often described as saucer- or cup-shaped particles. Urinary exosomes isolated by the double-cushion ultracentrifugation method have a similar morphology as single cell line derived exosomes. The transmission electron microscopy (TEM) image shows (Figure 5) that diameters of the vesicles purified in the $1 \mathrm{M}$ fraction are between 30 and $80 \mathrm{~nm}$. Interestingly, the shape of the exosomes appeared to be nearly spherical with only a few elongated or cup-shaped specimens. After the double-cushion ultracentrifugation the sample is basically free from the long uromodulin filaments known to contaminate UEs prepared by traditional methods.
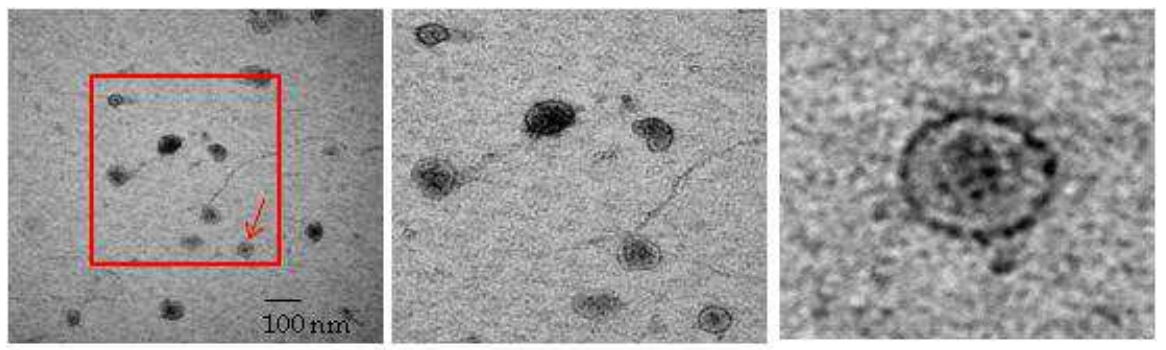

Fig. 5. Transmission electron microscopy image of urinary exosomes isolated and purified by the double-cushion ultracentrifugation method ( $1 \mathrm{M}$ fraction). The image shows the typical morphology and size distribution of the vesicles. Frame shows the enlarged image (central) and the arrow shows a single vesicle enlarged on the right image. 


\section{Quantitative proteomics of urinary exosomes for protein biomarker discovery}

Recently, we have developed protocols for lysis, protein extraction and in-solution digestion of UEs for MudPIT application to quantitative proteomics (Raj et al., 2011a). For the solubilization of exosomal membrane proteins the use of an acid cleavable detergent was found to be particularly useful. In a preliminary study four exosomal protein samples were prepared in parallel (Table 2) according to single- (sample 4) and double-cushion protocols (sample 1) from a pooled urine sample of 20 healthy donors (male, age group 25-45 years). Effects of age (sample 2) and sample pooling (sample 3) on the protein expression were also monitored in the same experiment.

\begin{tabular}{|c|c|c|c|c|}
\hline Sample & Age (years) & Number of samples & $\begin{array}{c}\text { Exosome preparation } \\
\text { method }\end{array}$ & Label \\
\hline 1 & $25-45$ & 20 & Double-cushion & iTRAQ-114 \\
\hline 2 & $50-70$ & 20 & Double-cushion & iTRAQ-115 \\
\hline 3 & 43 & 1 & Double-cushion & iTRAQ-116 \\
\hline 4 & $25-45$ & 20 & Single-cushion & iTRAQ-117 \\
\hline
\end{tabular}

Table 2. Samples analysed by in-solution digestion based MudPIT proteomics and iTRAQ labeling.

The 4-plex iTRAQ method (Ross et al., 2004) based on covalent labeling of the N-terminus and side-chain amines of peptides with four tags of varying mass was used for the protein quantitation (Figure 2.).

Protein samples were denatured, reduced, alkylated, enzymatically digested by trypsin and then labeled according to the manufacturer's protocol (iTRAQ reagent kit, Applied Biosystems). After iTRAQ labeling equal amounts of each sample (100 $\mu \mathrm{g})$ were mixed, vacuum dried, detergent was acid cleaved and the resulting sample was desalted. The purified sample was then separated by two-dimensional HPLC. For strong cation-exchange (SCX) chromatography, in the first dimension, the following conditions were used: $95 \%$ solvent A ( $20 \%$ acetonitrile, $0.05 \%$ formic acid) and $5 \%$ solvent B (20\% acetonitrile, $0.05 \%$ formic acid, $500 \mathrm{mM} \mathrm{KCl}$ ) for $3 \mathrm{~min}$, solvent $\mathrm{B}$ ramped up to $90 \%$ in $40 \mathrm{~min}$ and maintained at $100 \%$ for $7 \mathrm{~min}$. 47 fractions were collected between 0-55 min. Fractions were further separated in the second dimension on a reversed phase monolithic nano column using the following conditions: $95 \%$ solvent C ( $2 \%$ acetonitrile, $0.1 \%$ formic acid) and $5 \%$ solvent D ( $98 \%$ acetonitrile, $0.1 \%$ formic acid) for $5 \mathrm{~min}$, ramp to $50 \%$ solvent $\mathrm{D}$ in $90 \mathrm{~min}$ and in $6 \mathrm{sec}$ to $98 \%$ solvent D for $10 \mathrm{~min}$. Eluting peptides were analyzed online by a QTOF type of tandem mass spectrometer (Qstar Elite) in an information dependent acquisition mode which facilitates both the protein identification and the multiplex quantitative analysis of the four samples. Tandem mass spectra were extracted and peak lists were generated by Analyst QS 2.0 software using the default parameters. Peak lists containing all acquired MS/MS spectra were searched against SwissProt 2010_09 (519348 sequences) database using Mascot Server (version 2.2) with trypsin specificity and allowing for up to one missed cleavage. iTRAQ at lysine residue and the $\mathrm{N}$ termini of the peptides and carbamidomethylation of cysteines were considered as fixed modifications whereas oxidations of methionine and ITRAQ at tyrosine residues were set as possible variable modifications. Mass tolerance was set to $50 \mathrm{ppm}$ for precursor and to $0.1 \mathrm{Da}$ for fragment ions, respectively. Low molecular mass reporter ions were used to relatively quantify the 
peptides and the proteins from which they originate by Mascot iTRAQ 4-plex quantification method. Proteins which were quantified with a minimum of two unique peptides and $\mathrm{p}<0.05$ significance threshold using MudPIT scoring have been considered.

More than hundred proteins were quantified in the iTRAQ analysis. Table 3. shows the weighted median ratios of the first 25 proteins ranked by Mascot protein score. Expression level of the major proteins isolated and purified by the double-cushion method are different from those purified with the single-cushion protocol (Table 3., ratio 117/114). In particular, cytoskeletal proteins (cubulin, megalin, actin, cofillin, moesin, tubulin, etc.) seem to be less abundant in the sample. They may be due to heterogeneous constituents of the cytoskeleton filaments present in urine which co-purify with the UEs in traditional methods. On the other hand a marked enrichment was observed in proteins which are related to the VPS4 complex of ESCRT machinery (IST1, VPS4A, and VPS4B), its associated proteins (CHM2A, CHMP5,

\begin{tabular}{|l|l|c|c|c|c|}
\hline \multicolumn{1}{|c|}{ PrniProt ID } & \multicolumn{1}{|c|}{$\begin{array}{c}\text { Mascot } \\
\text { score }\end{array}$} & $\mathbf{1 1 5 / 1 1 4}$ & $\mathbf{1 1 6} / \mathbf{1 1 4}$ & $\mathbf{1 1 7 / 1 1 4}$ \\
\hline AMPN_HUMAN & Aminopeptidase & 1315 & 0.845 & 1.306 & 0.237 \\
\hline IST1_HUMAN & IST1 homolog & 656 & 1.037 & 0.706 & 0.406 \\
\hline ACTB_HUMAN & Actin, cytoplasmic & 430 & 1.408 & 1.631 & 0.733 \\
\hline DPEP1_HUMAN & Dipeptidase 1 & 370 & 0.857 & 0.700 & 0.430 \\
\hline VPS4A_HUMAN & $\begin{array}{l}\text { Vacuolar protein sorting-associated protein } \\
\text { 4A }\end{array}$ & 350 & 1.150 & 0.742 & 0.473 \\
\hline CHM2A_HUMAN & Charged multivesicular body protein 2a & 341 & 1.242 & 1.493 & 0.595 \\
\hline UROM_HUMAN & Uromodulin & 282 & 0.958 & 0.578 & 22.450 \\
\hline CHMP5_HUMAN & Charged multivesicular body protein 5 & 279 & 1.082 & 0.569 & 0.161 \\
\hline RS27A_HUMAN & Ubiquitin-40S ribosomal protein S27a & 275 & 1.051 & 0.764 & 0.445 \\
\hline GGT1_HUMAN & Gamma-glutamyltranspeptidase & 267 & 0.840 & 1.045 & 0.342 \\
\hline NEP_HUMAN & Neprilysin & 258 & 0.897 & 0.995 & 0.381 \\
\hline EZRI_HUMAN & Ezrin & 254 & 1.245 & 1.093 & 0.776 \\
\hline ANX11_HUMAN & Annexin A11 & 252 & 1.393 & 0.435 & 0.601 \\
\hline PSCA_HUMAN & Prostate stem cell antigen & 231 & 1.415 & 5.214 & 0.345 \\
\hline HSP7C_HUMAN & Heat shock cognate 71 kDa protein & 208 & 1.186 & 0.990 & 0.428 \\
\hline PDC6I_HUMAN & $\begin{array}{l}\text { Programmed cell death 6-interacting } \\
\text { protein }\end{array}$ & 231 & 1.093 & 0.684 & 0.500 \\
\hline CDC42_HUMAN & Cell division control protein 42 homolog & 208 & 1.044 & 1.773 & 0.190 \\
\hline VPS4B_HUMAN & $\begin{array}{l}\text { Vacuolar protein sorting-associated protein } \\
\text { 4B }\end{array}$ & 195 & 1.063 & 0.601 & 0.500 \\
\hline CHM4B_HUMAN & Charged multivesicular body protein 4b & 181 & 1.308 & 0.923 & 0.559 \\
\hline POTEF_HUMAN & POTE ankyrin domain family member F & 176 & 1.394 & 1.404 & 0.510 \\
\hline DPP4_HUMAN & Dipeptidyl peptidase 4 & 175 & 0.931 & 0.837 & 0.320 \\
\hline AQP1_HUMAN & Aquaporin-1 & 167 & 0.898 & 0.679 & 0.573 \\
\hline THY1_HUMAN & Thy-1 membrane glycoprotein & 151 & 1.316 & 2.332 & 0.354 \\
\hline MUC1_HUMAN & Mucin-1 & 0.945 & 0.523 & 0.743 \\
\hline PROM1_HUMAN & Prominin-1 & 1.014 & 0.655 & 0.500 \\
\hline
\end{tabular}

Table 3. The weighted median ratios of the 25 top-ranking proteins in the MudPIT based 4plex iTRAQ experiment. 114, 115, 116 and 117 indicate sample-labeling by iTRAQ according to Table 2. 
CHM4B) and proteins involved in the ubiquitination process (RS27A). The most abundant protein according to SDS-PAGE and MudPIT analyses is aminopeptidase (AMPN) known to reflect a periodicity in renal tubular function. Other proteins like AQP1, NEP, DPEP1 and DPP4 also related to renal function were identified among the most abundant proteins. Based on statistical analysis of the data, more than a 2-fold change was considered to be significant. Data obtained confirms that the double-cushion method efficiently removes the major urinary protein contamination characteristic of the current purification methods (more than a 20-fold change). In different single-cushion preparations (data not shown) the relative protein quantities vary considerably respect to that of uromodulin (i.e. mean of the fold changes of all quantified proteins unless uromodulin/uromodulin fold change). This can be explained by the poor reproducibility and it causes considerable complications in protein quantification and normalization. Comparing the two different age-groups we analysed, no significant difference in the expression was found in the 25 top-ranking exosomal proteins (Table 3., ratio 115/114). The individual sample, on the other hand shows few characteristic differences when compared with the pooled samples (116/114). In our study, the expression levels of PSCA and THY1 and ANX11 were found to be significantly altered respect to the age-matched control group. For a protein biomarker discovery platform which employs urinary exosomes as biomarker source, it is highly advisable to use a pooled control sample with a high number and clinically well defined individual samples.

\section{Conclusions}

Given the non-invasive nature of urine sample collection and the evolving biological significance of secreted membrane vesicles, unbiased quantitative analysis of biomolecules isolated from urinary exosomes is a step forward in clinical biomarker research. Recently we have set-up a multiplex quantitative approach for the analysis of protein contents of purified urinary exosomes (Figure 2.). This includes protocols for i.) the removal of major urinary exosome contaminations, ii.) the separation of urinary membrane vesicles of different sizes iii.) vesicle lysis and protein solubilization and, iv) the quantitative proteomics based urinary exosomal biomarker research. The novel isolation/purification procedure efficiently removes the major urinary exosomal contaminations and separates exosomes from other membrane vesicles. Thus it provides a good basis for the development of optimized methods for protein biomarker research. Quantitative MudPIT analysis performed on biological, analytical and technical replicates shows excellent reproducibility. No significant expression difference was found among normal healthy subjects grouped by age. Preliminary data suggests a superior performance in single sample biomarker analysis design over a pooling design. All together, these results suggest a prolific future of urinary exosomes in clinical proteomics of different diseases involving the renal and urinary tract.

\section{Acknowledgment}

The authors are grateful for the financial contribution of Italian Society of Nephrology granted by "Ricercando 2011" for the project entitled "Identification of reliable urinary biomarkers of Diabetic Nephropathy by means of powerful and complementary proteomic strategies". We also thank Rosarita Tatè and Michele Cermola (IGB, CNR) for the TEM analysis. 


\section{References}

Babst, M. (2011). MVB vesicle formation: ESCRT-dependent, ESCRT-independent and everything in between. Current Opinion in Cell Biology, In Press, Corrected Proof.

Camussi, G., Deregibus, M. C., Bruno, S., Cantaluppi, V. \& Biancone, L. (2011). Exosomes/microvesicles as a mechanism of cell-to-cell communication. Kidney International, 78 (9), 838-848.

Cheruvanky, A., Zhou, H., Pisitkun, T., Kopp, J. B., Knepper, M. A., Yuen, P. S. T. \& Star, R. A. (2007). Rapid isolation of urinary exosomal biomarkers using a nanomembrane ultrafiltration concentrator. American Journal of Physiololgy Renal Physiology, 292 (5), F1657-1661.

Denzer, K., Kleijmeer, M. J., Heijnen, H. F., Stoorvogel, W. \& Geuze, H. J. (2000). Exosome: from internal vesicle of the multivesicular body to intercellular signaling device. Journal of Cell Science, 113 (19), 3365-3374.

Fernandez-Llama, P., Khositseth, S., Gonzales, P. A., Star, R. A., Pisitkun, T. \& Knepper, M. A. (2010). Tamm-Horsfall protein and urinary exosome isolation. Kidney International, 77 (8), 736-742.

Gan, X. \& Gould, S. J. (2011). Identification of an inhibitory budding signal that blocks the release of HIV particles and exosome/microvesicle proteins. Molecular Biology of the Cell, 22 (6), 817-830.

Gonzales, P., Pisitkun, T. \& Knepper, M. A. (2008). Urinary exosomes: is there a future? Nephrology Dialysis Transplantation, 23 (6), 1799-1801.

Gonzales, P. A., Pisitkun, T., Hoffert, J. D., Tchapyjnikov, D., Star, R. A., Kleta, R., Wang, N. S. \& Knepper, M. A. (2009). Large-Scale Proteomics and Phosphoproteomics of Urinary Exosomes. Journal of the American Society of Nephrology, 20 (2), 363-379.

Gruenberg, J. \& Stenmark, H. (2004). The biogenesis of multivesicular endosomes. Nature Reviews Molecular Cell Biology, 5 (4), 317-323.

Gutwein, P., Schramme, A., Abdel-Bakky, M., Doberstein, K., Hauser, I., Ludwig, A., Altevogt, P., Gauer, S., Hillmann, A., Weide, T., Jespersen, C., Eberhardt, W. \& Pfeilschifter, J. (2010). ADAM10 is expressed in human podocytes and found in urinary vesicles of patients with glomerular kidney diseases. Journal of Biomedical Science, 17 (1), 3.

Hogan, M. C., Manganelli, L., Woollard, J. R., Masyuk, A. I., Masyuk, T. V., Tammachote, R., Huang, B. Q., Leontovich, A. A., Beito, T. G., Madden, B. J., Charlesworth, M. C., Torres, V. E., LaRusso, N. F., Harris, P. C. \& Ward, C. J. (2009). Characterization of PKD Protein-Positive Exosome-Like Vesicles. Journal of the American Society of Nephrology, 20 (2), 278-288.

Keller, S., Ridinger, J., Rupp, A.-K., Janssen, J. \& Altevogt, P. (2011). Body fluid derived exosomes as a novel template for clinical diagnostics. Journal of Translational Medicine, 9 (1), 86.

Keller, S., Rupp, C., Stoeck, A., Runz, S., Fogel, M., Lugert, S., Hager, H. D., Abdel-Bakky, M. S., Gutwein, P. \& Altevogt, P. (2007). CD24 is a marker of exosomes secreted into urine and amniotic fluid. Kidney International, 72 (9), 1095-1102.

Keller, S., Sanderson, M. P., Stoeck, A. \& Altevogt, P. (2006). Exosomes: From biogenesis and secretion to biological function. Immunology Letters, 107 (2), 102-108.

Kobayashi, K. \& Fukuoka, S. (2001). Conditions for Solubilization of Tamm-Horsfall Protein/Uromodulin in Human Urine and Establishment of a Sensitive and 
Accurate Enzyme-Linked Immunosorbent Assay (ELISA) Method. Archives of Biochemistry and Biophysics, 388 (1), 113-120.

Lee, T., D'Asti, E., Magnus, N., Al-Nedawi, K., Meehan, B. \& Rak, J. (2011). Microvesicles as mediators of intercellular communication in cancer-the emerging science of cellular 'debris'. Seminars in Immunopathology, 1-13.

Li, J. Y., Yong, T. Y., Michael, M. Z. \& Gleadle, J. M. (2010). Review: The role of microRNAs in kidney disease. Nephrology, 15 (6), 599-608.

Li, X.-B., Zhang, Z.-R., Schluesener, H. J. \& Xu, S.-Q. (2006). Role of exosomes in immune regulation. Journal of Cellular and Molecular Medicine, 10 (2), 364-375.

Li, Y., Zhang, Y., Qiu, F. \& Qiu, Z. (2011). Proteomic identification of exosomal LRG1: A potential urinary biomarker for detecting NSCLC. Electrophoresis, 32, 1-8.

Marsh, M. \& van Meer, G. (2008). No ESCRTs for Exosomes. Science, 319 (5867), 1191-1192.

Mathivanan, S., Lim, J. W. E., Tauro, B. J., Ji, H., Moritz, R. L. \& Simpson, R. J. (2010). Proteomics Analysis of A33 Immunoaffinity-purified Exosomes Released from the Human Colon Tumor Cell Line LIM1215 Reveals a Tissue-specific Protein Signature. Molecular \& Cellular Proteomics, 9 (2), 197-208.

Mathivanan, S. \& Simpson, R. J. (2009). ExoCarta: A compendium of exosomal proteins and RNA. Proteomics, 9 (21), 4997-5000.

Merchant, M. L., Powell, D. W., Wilkey, D. W., Cummins, T. D., Deegens, J. K., Rood, I. M., McAfee, K. J., Fleischer, C., Klein, E. \& Klein, J. B. (2010). Microfiltration isolation of human urinary exosomes for characterization by MS. Proteomics - Clinical Applications, 4 (1), 84-96.

Miranda, K. C., Bond, D. T., McKee, M., Skog, J., Paunescu, T. G., Da Silva, N., Brown, D. \& Russo, L. M. (2010). Nucleic acids within urinary exosomes/microvesicles are potential biomarkers for renal disease. Kidney International, 78 (2), 191-199.

Mitchell, P., Welton, J., Staffurth, J., Court, J., Mason, M., Tabi, Z. \& Clayton, A. (2009). Can urinary exosomes act as treatment response markers in prostate cancer? Journal of Translational Medicine, 7 (1), 4.

Nilsson, J., Skog, J., Nordstrand, A., Baranov, V., Mincheva-Nilsson, L., Breakefield, X. O. \& Widmark, A. (2009). Prostate cancer-derived urine exosomes: a novel approach to biomarkers for prostate cancer. British Journal of Cancer, 100 (10), 1603-1607.

Pisitkun, T., Shen, R.-F. \& Knepper, M. A. (2004). Identification and proteomic profiling of exosomes in human urine. Proceedings of the National Academy of Sciences of the United States of America, 101 (36), 13368-13373.

Porter, K. R. \& Tamm, I. (1955). Direct visualization of a mucoprotein component of urine. Journal of Biological Chemistry, 212 (1), 135-140.

Raj, D. A. A., Capasso, G., Fiume, I. \& Pocsfalvi, G. (2011a). A multiplex quantitative proteomics strategy for protein biomarker studies in urinary exosomes Kidney International, accepted, manuscript ID: KI-09-11-1553.R1.

Raj, D. A. A., Capasso, G., Fiume, I. \& Pocsfalvi, G. (2011b). Procedura di isolamento e di purificazione degli esosomi urinari per la ricerca di biomarcatori proteici. In U. I. B. M. patent deposited in 14 March 2011 (ed.), Ufficio Italiano Brevetti e Marchi, Italy.

Raposo, G. a., Tenza, D., Murphy, D. M., Berson, J. F. \& Marks, M. S. (2001). Distinct Protein Sorting and Localization to Premelanosomes, Melanosomes, and Lysosomes in Pigmented Melanocytic Cells. The Journal of Cell Biology, 152 (4), 809-824. 
Rood, I. M., Deegens, J. K. J., Merchant, M. L., Tamboer, W. P. M., Wilkey, D. W., Wetzels, J. F. M. \& Klein, J. B. (2010). Comparison of three methods for isolation of urinary microvesicles to identify biomarkers of nephrotic syndrome. Kidney Int, 78 (8), 810816.

Ross, P. L., Huang, Y. N., Marchese, J. N., Williamson, B., Parker, K., Hattan, S., Khainovski, N., Pillai, S., Dey, S., Daniels, S., Purkayastha, S., Juhasz, P., Martin, S., BartletJones, M., He, F., Jacobson, A. \& Pappin, D. J. (2004). Multiplexed Protein Quantitation in Saccharomyces cerevisiae Using Amine-reactive Isobaric Tagging Reagents. Molecular \& Cellular Proteomics, 3 (12), 1154-1169.

Schaeffer, C., Santambrogio, S., Perucca, S., Casari, G. \& Rampoldi, L. (2009). Analysis of Uromodulin Polymerization Provides New Insights into the Mechanisms Regulating ZP Domain-mediated Protein Assembly. Molecular Biology of the Cell, 20 (2), 589-599.

Shen, B., Wu, N., Yang, J.-M. \& Gould, S. J. (2011). Protein targeting to exosomes/microvesicles by plasma membrane anchors. Journal of Biological Chemistry.

Simpson, R. J., Lim, J. W. E., Moritz, R. L. \& Mathivanan, S. (2009). Exosomes: proteomic insights and diagnostic potential. Expert Review of Proteomics, 6 (3), 267-283.

Smalley, D. M., Sheman, N. E., Nelson, K. \& Theodorescu, D. (2008). Isolation and Identification of Potential Urinary Microparticle Biomarkers of Bladder Cancer. Journal of Proteome Research, 7 (5), 2088-2096.

Sonoda, H., Yokota-Ikeda, N., Oshikawa, S., Kanno, Y., Yoshinaga, K., Uchida, K., Ueda, Y., Kimiya, K., Uezono, S., Ueda, A., Ito, K. \& Ikeda, M. (2009). Decreased abundance of urinary exosomal aquaporin-1 in renal ischemia-reperfusion injury. American Journal of Physiology - Renal Physiology, 297 (4), F1006-F1016.

Taylor, D. D. L., KY, US), Gercel-taylor, Cicek (Louisville, KY, US) (2010). Exosomeassociated micro RNA as a dignostic marker. United States: University of Lousville ResearchFoundation Inc. (Louisville, KY, US).

Thery, C., Zitvogel, L. \& Amigorena, S. (2002). Exosomes: composition, biogenesis and function. Nature reviews, 2, 569 - 579.

Trajkovic, K., Hsu, C., Chiantia, S., Rajendran, L., Wenzel, D., Wieland, F., Schwille, P., Brugger, B. \& Simons, M. (2008). Ceramide Triggers Budding of Exosome Vesicles into Multivesicular Endosomes. Science, 319 (5867), 1244-1247.

Utleg, A. G., Yi, E. C., Xie, T., Shannon, P., White, J. T., Goodlett, D. R., Hood, L. \& Lin, B. (2003). Proteomic analysis of human prostasomes. The Prostate, 56 (2), 150-161.

Valadi, H., Ekstrom, K., Bossios, A., Sjostrand, M., Lee, J. J. \& Lotvall, J. O. (2007). Exosomemediated transfer of mRNAs and microRNAs is a novel mechanism of genetic exchange between cells. Nature Cell Biology, 9 (6), 654-659.

van Niel, G., Porto-Carreiro, I., Simoes, S. \& Raposo, G. (2006). Exosomes: A Common Pathway for a Specialized Function. Journal of Biochemistry, 140 (1), 13-21.

Welton, J. L., Khanna, S., Giles, P. J., Brennan, P., Brewis, I. A., Staffurth, J., Mason, M. D. \& Clayton, A. (2010). Proteomic analysis of bladder cancer exosomes. Molecular $\mathcal{E}$ Cellular Proteomics.

Williams, R. L. \& Urbe, S. (2007). The emerging shape of the ESCRT machinery. Nature Reviwes Molecular Cell Biology, 8 (5), 355-368. 
Zhou, H., Cheruvanky, A., Hu, X., Matsumoto, T., Hiramatsu, N., Cho, M. E., Berger, A., Leelahavanichkul, A., Doi, K., Chawla, L. S., Illei, G. G., Kopp, J. B., Balow, J. E., Austin, H. A., III, Yuen, P. S. T. \& Star, R. A. (2008). Urinary exosomal transcription factors, a new class of biomarkers for renal disease. Kidney International, 74 (5), 613621.

Zhou, H., Pisitkun, T., Aponte, A., Yuen, P. S. T., Hoffert, J. D., Yasuda, H., Hu, X., Chawla, L., Shen, R. F., Knepper, M. A. \& Star, R. A. (2006a). Exosomal Fetuin-A identified by proteomics: A novel urinary biomarker for detecting acute kidney injury. Kidney International, 70 (10), 1847-1857.

Zhou, H., Yuen, P. S. T., Pisitkun, T., Gonzales, P. A., Yasuda, H., Dear, J. W., Gross, P., Knepper, M. A. \& Star, R. A. (2006b). Collection, storage, preservation, and normalization of human urinary exosomes for biomarker discovery. Kidney International, 69 (8), 1471-1476. 


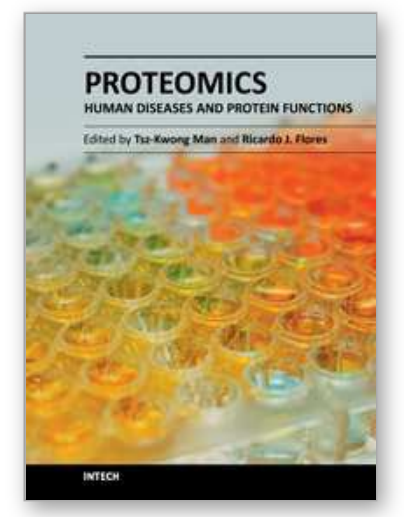

\author{
Proteomics - Human Diseases and Protein Functions \\ Edited by Prof. Tsz Kwong Man
}

ISBN 978-953-307-832-8

Hard cover, 438 pages

Publisher InTech

Published online 10, February, 2012

Published in print edition February, 2012

Biomedical research has entered a new era of characterizing a disease or a protein on a global scale. In the post-genomic era, Proteomics now plays an increasingly important role in dissecting molecular functions of proteins and discovering biomarkers in human diseases. Mass spectrometry, two-dimensional gel electrophoresis, and high-density antibody and protein arrays are some of the most commonly used methods in the Proteomics field. This book covers four important and diverse areas of current proteomic research: Proteomic Discovery of Disease Biomarkers, Proteomic Analysis of Protein Functions, Proteomic Approaches to Dissecting Disease Processes, and Organelles and Secretome Proteomics. We believe that clinicians, students and laboratory researchers who are interested in Proteomics and its applications in the biomedical field will find this book useful and enlightening. The use of proteomic methods in studying proteins in various human diseases has become an essential part of biomedical research.

\title{
How to reference
}

In order to correctly reference this scholarly work, feel free to copy and paste the following:

Delfin Albert Amal Raj, Immacolata Fiume, Giovambattista Capasso and Gabriella Pocsfalvi (2012). Urinary Exosomes for Protein Biomarker Research, Proteomics - Human Diseases and Protein Functions, Prof. Tsz Kwong Man (Ed.), ISBN: 978-953-307-832-8, InTech, Available from:

http://www.intechopen.com/books/proteomics-human-diseases-and-protein-functions/urinary-exosomes-forprotein-biomarker-research

\section{INTECH}

open science | open minds

\section{InTech Europe}

University Campus STeP Ri

Slavka Krautzeka 83/A

51000 Rijeka, Croatia

Phone: +385 (51) 770447

Fax: +385 (51) 686166

www.intechopen.com

\section{InTech China}

Unit 405, Office Block, Hotel Equatorial Shanghai

No.65, Yan An Road (West), Shanghai, 200040, China

中国上海市延安西路65号上海国际贵都大饭店办公楼405单元

Phone: +86-21-62489820

Fax: $+86-21-62489821$ 
(C) 2012 The Author(s). Licensee IntechOpen. This is an open access article distributed under the terms of the Creative Commons Attribution 3.0 License, which permits unrestricted use, distribution, and reproduction in any medium, provided the original work is properly cited. 